\title{
Design and simulation of High Voltage Gain current fed full-bridge voltage doubler Converter Fed Multilevel Inverter for Fuel Cell Powered Electric Vehicle
}

\author{
J.S.V. Siva Kumar ${ }^{1}$, K. Manoj Kumar Reddy ${ }^{2}$, M. Premkumar ${ }^{3}$, P. Mallikarjuna Rao ${ }^{4}$ \\ ${ }^{1}$ Assistant Professor, GMRIT, India, jsvsivakumar99@gmail.com \\ ${ }^{2}$ Assosiate Professor, Aditya College of Engineering, India, kmkreddyy@ gmail.com \\ ${ }^{3}$ Assistant Professor, GMRIT, India, India, mprem.me@gmail.com \\ ${ }^{4}$ Professor, Andhra University, India, electricalprofessor@gmail.com
}

\begin{abstract}
Nowadays in traditional vehicles the cost of fuel (petrol, diesel, gas, etc.) Increases, fuel supply, decreases, causing more air pollution and often low performance with high operating noise. Battery-based vehicles minimize carbon emissions but have a short driving range and long charging time limitations. Fuel cell electric vehicle consists of two Conversion stages; the conversions are DC-DC and DC-AC. In that, the conversion to DC-AC is done via an inverter. Coming to DC-DC conversion, various topologies such as fly-back, forward, and full-bridge converters have been proposed to get boosted DC. This paper concentrates on a Hybrid Boost current supplied with full-bridge voltage doubler topology Instead of using non-isolated high-frequency converters for DC conversion and designing diode clamped multilevel inverters using phase disposition technique to minimize the THD in AC output voltage. The proposed topology can reduce ripples of input current, reduce complexity control, and reduced loss of conduction. The proposed converter uses ZVS and ZVS switching techniques to reduce conductive losses and uses interleaved architecture to improve reliability and efficiency. The effectiveness of the proposed control scheme may be verified through PSIM 9.0.4 software.
\end{abstract}

Keywords: Fuel Cell, ZVS \&ZCS, Diode Clamped Multilevel Inverter, Electric Vehicle.

\section{INTRODUCTION}

Recently, the use of renewable energy has been growing increasingly compared to traditional sources due to the demand for sustainable energy. Fossil fuels can be fully used by the year 2050 according to environmental summits. We should, therefore reserve those sources for generations to come and offer priority to generating electricity using renewable resources. Wind, Photovoltaic, fuel cells, and others are renewable energy choices. The fuel cell sources are powerful, easy, and reliable to produce electricity onboard a vehicle [1]. The circuit diagram for a fuel-cell-powered electric vehicle is depicted in Fig 1. The use of higher rating applications such as EV is not necessary for a single cell output voltage.

Consequently, each cell is connected in parallel and series to get the required high dc voltage. So, the high voltage gain converters dc to dc are required to utilize EV applications [2]. By using these low voltages (24-67 V) can step up to high voltages $(301-500 \mathrm{~V})$. A large transfer gain and high performance are the salient features of this converter. A high voltage achievement is provided by traditional boost converters dependent on theoretical estimates, with an extreme duty ratio. The converters, however, operate with a high duty ratio due to poor efficiency, EMI and reverse recovery problems [3][4]. Many of the converters are isolated, such as push-pull, fly-back, and forward, which can be accomplished by changing the transformer turns ratio with high voltage gain.

Two forms of the converters exist, such as 1. Isolated and, 2. Non-isolated converters. Electrically separated between the input and the output terminals are in isolated converters, whereas they are not separated from the common ground in Nonisolated. Based on the form of standard, the isolated converters have high voltage insulation from several hundred to thousand volts. These converters are very strong noise and interfacing blocking capability, thus providing the load with a cleaner DC source provided by several sensitive loads.

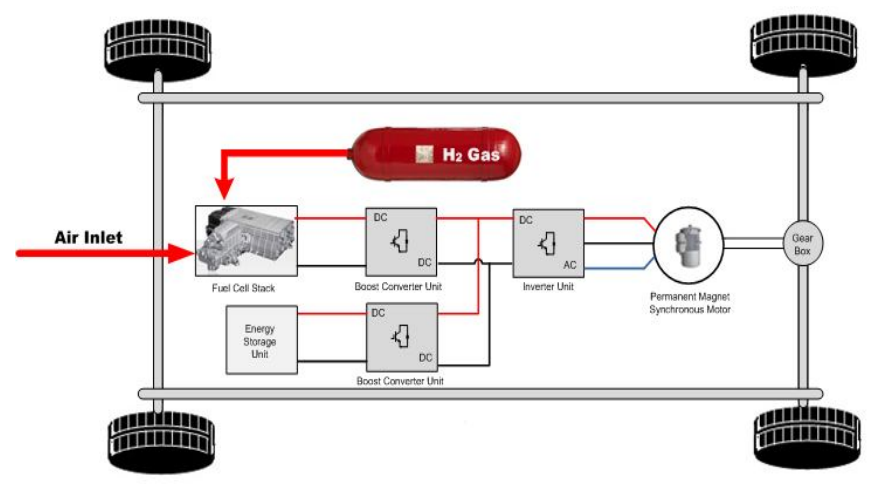

Figure1: Diagram of the FCEV 
In the last few decades in many industrial applications, the multilevel inverters are used because of advantages. This is because of new topologies are developed, and research is going in these topics. The main aim of this study is to give the importance of the concept of multilevel inverter and its applications. This paper provides a brief overview of well-established multilevel inverters in EV applications which are highly oriented towards their current state. Recently, the main reasons for multilevel inverters have attracted increasing interest are: power ratings are increased, improved harmonic efficiency, and emissions of electromagnetic interference (EMI) is reduced that can be archived with multiple dc rates synthesizing waveform of the output voltage. Multilevel inverters have high priority EV, medium industrial drives and PV grid-connected system [5]-[7]. In the present work, the utilization of multilevel inverter output for EV is explained with less THD with simulations.

\section{CURRENT FED FULL BRIDGE DC-DC BOOST CONVERTER}

The current fed dc-dc full-bridge converter plays a vital role in connecting the auxiliary source with the primary power source to achieve the subsequent needs. a) HF transformer turns ratio is high to boost low battery terminal voltage to dc bus (150-300) V adjustable high-voltage fuel-cell bus. b) Satisfy the bidirectional flow of electricity. The converter should have the capacity to provide energy in the forward direction during a steady start-up and transition process and consume energy in the reverse direction during regenerative braking. c) Capacity to handle high power. d) the size and volume are reduced by high frequency (HF) operation with high power density. e) High efficiency.

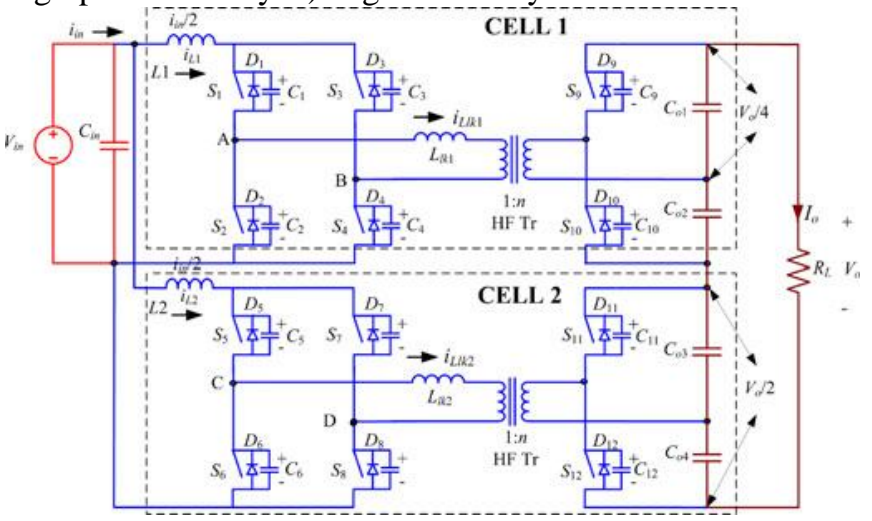

Figure 2: Proposed interleaved ZCS current-fed dc-dc full-bridge converter

Limitations of voltage fed controllers are input current is high pulsating, switching range is limited, Ringing diode rectifier, loss of duty cycle, low efficiency, for applications for high input current and voltage amplification. By using Current fed controllers, these limitations can be overcome. Because of the leakage inductance stored energy, the major disadvantage of current fed converters is during turn off high voltage spike at the device. The passive snubber called RCD snubber is placed to reduce voltage spike. An active clamp circuit is utilized, which contains a condenser and power switch to clamp the voltage, and it can achieve ZVZCS. High current tension and high flowing current at light charge level are the major drawbacks.

When switching off the diagonal switching pairs from the primary side of cell1 and cell2, another pair must be switched on in this article. The transformer's secondary side voltage is $\mathrm{V} 0 / 4$, due to transformer behavior would be mirrored to the primary side by a value $\mathrm{V} 0 / 4 \mathrm{n}$. This voltage averts the current from one switch pair to another, instigating one pair of switches to fall and another pair of switches to rise. Afterward, the body diodes begin conduction, and the switch gating signals are detached, leading to ZCS turning off the system. In cell1, the primary side switching pairs S1-S4 and S2-S3shoud are operated with a duty cycle of more than 50 percent and operated with the same gate signals phase-shifted by $180^{\circ}$. Similarly, in cell2 switching pairs, S5-S8 and S6-S7 are operated with the same gate signals phase-shifted by $180^{\circ}$. The difference in phase between S1-S4 gating signals in cell 1 and S5-S8 gating signals in cell 2 is $90^{\circ}$.

Merits of this proposed converter are given below:

1. The switches are operated at ZCS on the primary side, ZVS on the secondary side so that switching losses will be reduced, and a high switching frequency of operation size and cost of the system reduces.

2. The voltage is independent of the service cycle of varying input voltage and output power through primary side circuits. This avoids a passive snubber circuit or an active clamped circuit. So, the conduction losses will be reduced, and efficiency will be improved.

3. With the interleaved design, the reliability and the power handling capacity will be increases. Failure of one of the cells, the system will deliver $50 \%$ of the rated power.

4. Due to the high ripple frequency, the size of the passive components like input and output filters is reduced.

5. Satisfies bidirectional power flow. The converter operates in the forward direction as a current-fed converter and behaves as a half-fed voltage-bridge-isolated dc-dc converter with an inductive reverse-direction output filter.

\section{CONVERTER DESIGN}

For designing the proposed converter, The considered values are given $\mathrm{V}_{\text {in }}=12 \mathrm{~V}, \mathrm{~V}_{0}=150-300 \mathrm{~V}, \mathrm{~N}_{\text {ominal }}=300 \mathrm{~V}, \mathrm{P}_{0}=500 \mathrm{~W}$, and $\mathrm{f}_{\mathrm{s}}=100 \mathrm{KHz}$.

The input average current is, $I_{i n}=\frac{P_{0}}{\eta \cdot V_{i n}}$

Considering the ideal efficiency $\eta$ of $95 \%$, then $\mathrm{I}_{\text {in }}=43.9 \mathrm{~A}$.

The primary switches' maximum voltage is $V_{P, S W}=\frac{V_{0}}{4 . n}$. 
J.S.V. Siva Kumar et al., International Journal of Emerging Trends in Engineering Research, 8(9), September 2020, 6191 - 6195

The voltage conversion ratio is $V_{0}=\frac{2 \cdot \mathrm{n} \cdot \mathrm{V}_{\text {in }}}{1-d}$.

The transformer leakage inductance $\mathrm{L}_{\mathrm{lk}}$ is calculated by using the following equation.

$L_{l k}=\frac{V_{0} \cdot(d-0.5)}{4 . n \cdot I_{i n} \cdot \mathrm{f}_{s}}$.

The RMS value of current flowing in primary switches is $I_{P, r m s}=\frac{I_{\text {in }}}{2} \sqrt{\frac{2-d}{3}}$.

Then $\mathrm{I}_{\mathrm{P}, \mathrm{rms}}=13.85 \mathrm{~A}$. The power output can be expressed as, $P_{0}=\frac{4 n \cdot v_{i n}^{2}-v_{0} \cdot v_{i n} \cdot(3-4 \mathrm{~d})}{16 \cdot n \cdot \mathrm{L}_{l k} \cdot f_{s}}$.

A large turns ratio of the transformer reduces the maximum voltage across the primary switches. By which voltage rating is reduced for the switches. As the turn's ratio increases, the transformer's leakage inductance decreases, thus increasing the converter's power transfer capability. The optimal service ratio $\mathrm{d}=0.8$ and turns ratio $\mathrm{n}=2.5$ was selected to get small overall conduction losses.

The RMS value of the current flowing in the HF transformer's primary winding is

$I_{\text {Llk,rms }}=\frac{I_{\text {in }}}{2} \sqrt{\frac{5-4 d}{3}}$.

Then $\mathrm{I}_{\mathrm{Ll}, \mathrm{rms}}=17 \mathrm{~A}$.

The boost inductor value is given by $L=\frac{V_{i n} \cdot(\mathrm{d}-0.5)}{\Delta I . \mathrm{f}_{S}}$

Where $\Delta \mathrm{I}$ is the ripple current of the boost inductor. Given $\Delta \mathrm{I}=1 \mathrm{~A}, \mathrm{~L}=36 \mu \mathrm{H}$.

The average and RMS value of current flowing in the secondary devices body diodes are $\bar{i}_{D}=\frac{I_{i n} \cdot(7-6 \mathrm{~d})}{16 n}$

$I_{D, r m s}=\frac{I_{i n}}{4 n} \sqrt{\frac{11-10 d}{3}}$.

Then $\mathrm{I}_{\mathrm{D}, \mathrm{rms}}=4.39$.

The RMS value of current which is flowing in the secondary side devices is $I_{S, r m s}=\frac{I_{i n}}{4 n} \sqrt{\frac{2 d-1}{3}}$.

Then $\mathrm{I}_{\mathrm{S}, \mathrm{rms}}=1.96 \mathrm{~A}$.

The secondary side devices voltage rating is $\mathrm{V}_{0} / 2=150 \mathrm{~V}$.

Each HF transformer VA rating is given by

$V A_{\text {trans }}=\frac{V_{0} \cdot I_{\text {in }}}{8 n} \sqrt{\frac{2 \cdot(5-4 \mathrm{~d}) \cdot(1-\mathrm{d})}{3}}$.

Then $\mathrm{VA}_{\text {trans }}=321.9 \mathrm{VA}$.

\section{NEUTRAL POINT DIODE CLAMPED FIVE-LEVEL MULTILEVEL INVERTER}

Fig. 3 shows a Diode clamped Five-Level multilevel inverters. Switches S1 to S4 will conduct simultaneously to bring $\mathrm{V} \mathrm{dc} / 2$ into the stream. Four switches will conduct for increasing voltage levels. As shown in Table.1, the output maximum voltage is half the DC source [8]. The angles of the switching should be calculated so that the output voltage THD becomes as low as possible. The method of measuring the switching angle used in this paper is the method of harmonic elimination. In this process, the harmonics in lower order can be removed by choosing measured switching angles [8].

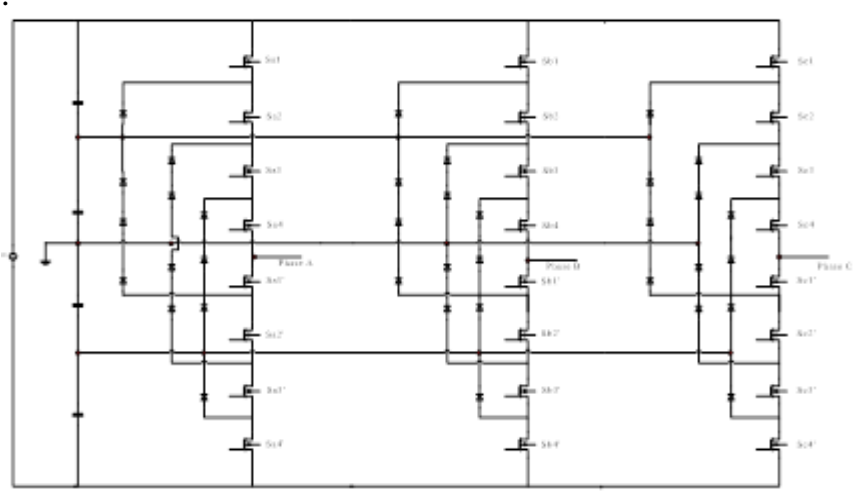

Figure 3: Diode clamped Five-Level multi-level Inverter

TABLE I: SWITCHING STRUCTURE OF DIODE CLAMPED FIVE-LEVEL MULTILEVEL INVERTER

\begin{tabular}{|l|l|l|l|l|l|l|l|l|}
\hline $\mathbf{S}_{\mathbf{1}}$ & $\mathbf{S}_{\mathbf{2}}$ & $\mathbf{S}_{\mathbf{3}}$ & $\mathbf{S}_{\mathbf{4}}$ & $\mathbf{S}_{\mathbf{1}}{ }^{\mathbf{I}}$ & $\mathbf{S}_{\mathbf{2}}{ }^{\mathbf{I}}$ & $\mathbf{S}_{\mathbf{3}}{ }^{\mathbf{I}}$ & $\mathbf{S}_{\mathbf{4}}{ }^{\mathbf{I}}$ & $\mathbf{V}_{\mathbf{0}}$ \\
\hline 1 & 1 & 1 & 1 & 0 & 0 & 0 & 0 & $\mathrm{~V}_{\mathrm{dc}} / 2$ \\
\hline 0 & 1 & 1 & 1 & 1 & 0 & 0 & 0 & $\mathrm{~V}_{\mathrm{dc}} / 4$ \\
\hline 0 & 0 & 1 & 1 & 1 & 1 & 0 & 0 & 0 \\
\hline 0 & 0 & 0 & 1 & 1 & 1 & 1 & 0 & $-\mathrm{V}_{\mathrm{dc}} / 4$ \\
\hline 0 & 0 & 0 & 0 & 1 & 1 & 1 & 1 & $-\mathrm{V}_{\mathrm{dc}} / 2$ \\
\hline
\end{tabular}

The modulation index of Multi-carrier PWM the amplitude is $m_{a}=\frac{2 A_{m}}{(\mathrm{~m}-1) A_{c}}$, where $\mathrm{A}_{\mathrm{m}}$ is the modulating signal amplitude, and $A_{c}$ is the carrier signal. The frequency modulation index of Multi-carrier PWM is $m_{f}=\frac{f_{c}}{f_{m}}$

where $\mathrm{fc}$ is the frequency of the carrier signal, and $\mathrm{f}_{\mathrm{m}}$ is the frequency of the modulating signal. In this paper, the carrier signal frequency is $4 \mathrm{kHz}$, and a modulating signal frequency is $50 \mathrm{~Hz}$. Fig. 4 shows how the gate pulses are developed for DCMLI, and gating pulses are shown in Fig. 5. 


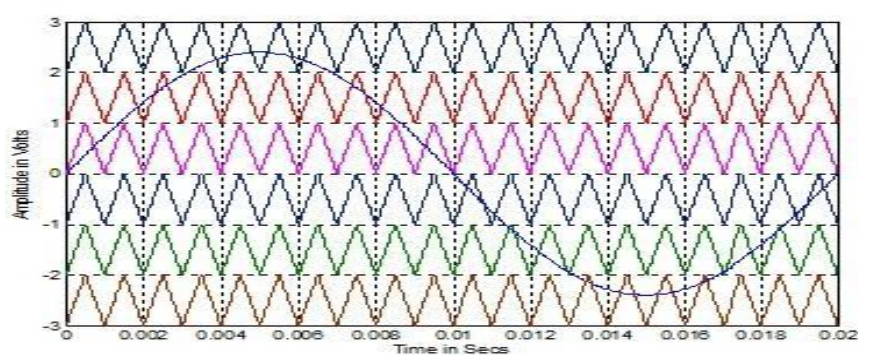

Figure 4: generation of gate pulses using PDPWM method.

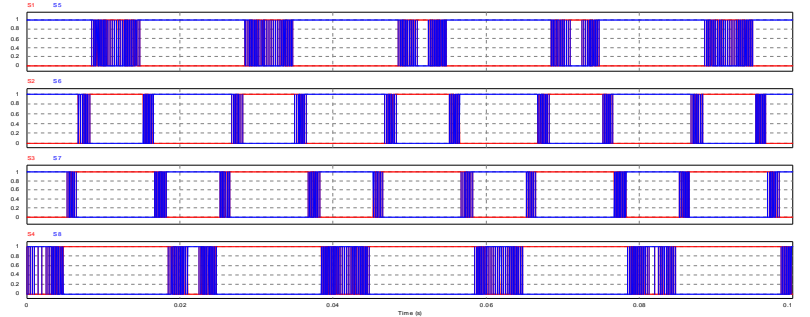

Figure 5: gate pulses given to the inverter switches

\section{SIMULATION RESULTS}

The output voltage of fuel cells is connected to the boost converter as its input. The output of the boost converter is connected as an input to the multilevel inverter clamped 5 -level diode to get ac voltage. The output voltage of $300 \mathrm{~V}$ is obtained for a given input voltage of $12 \mathrm{~V}$, it is shown in Fig 6 , and the gating pulses are shown in Fig.8.

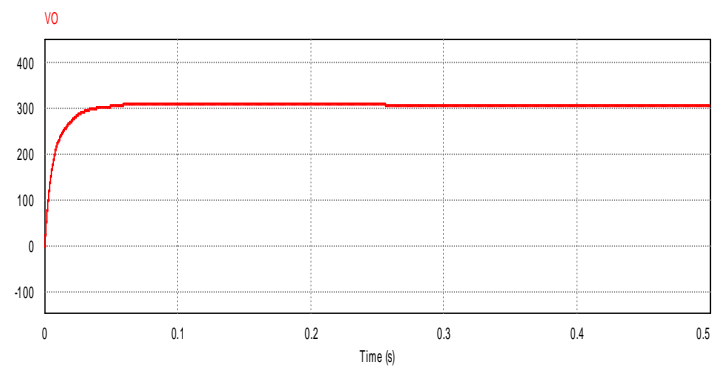

Figure 6: Boost converter Output Voltage.

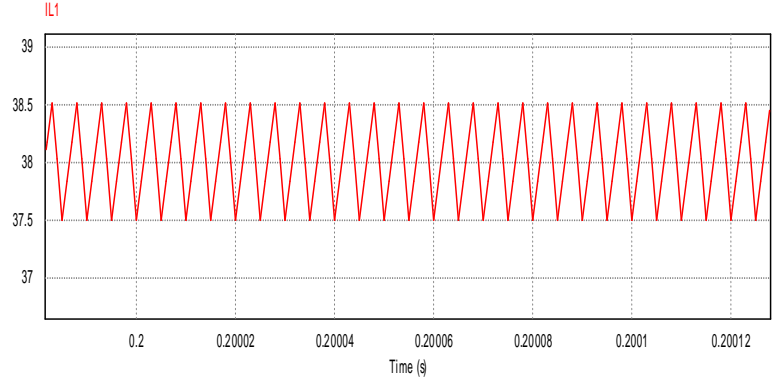

Figure 7: Inductor Current $I\left(L_{1}\right)$

From the above result inductor, the current ripple is nearly one amp its shown in Fig 7.

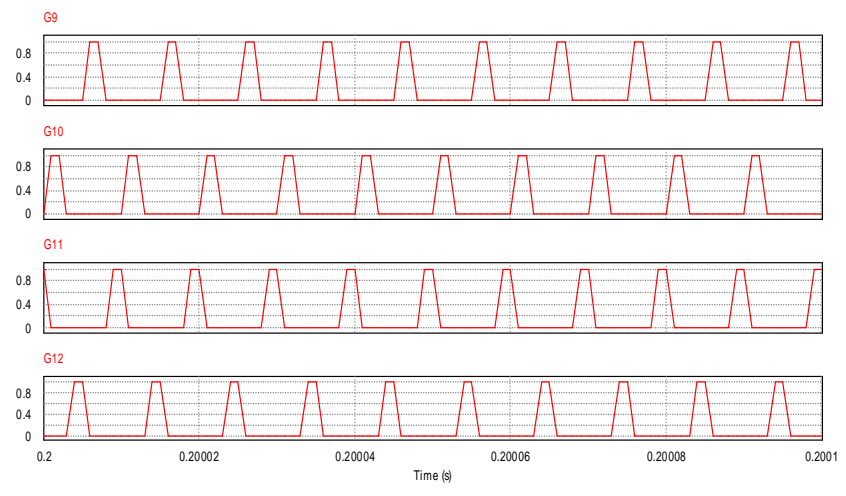

(a)

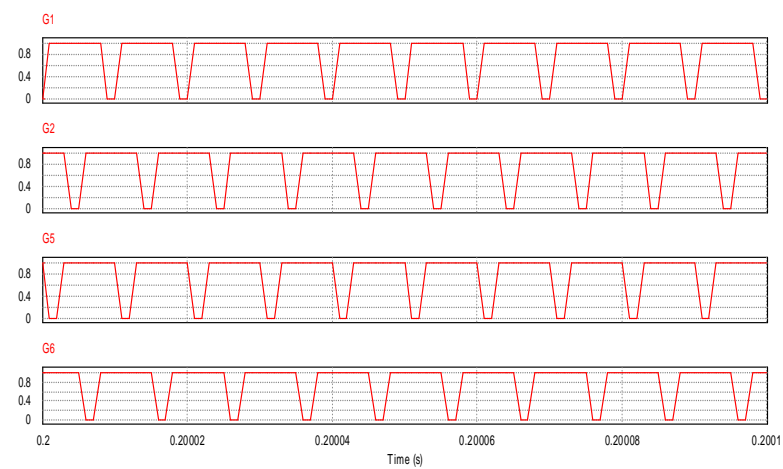

(b)

Figure 8: Given Pulses to switches; (a) Switches of Primary-side. (b) Switches of Secondary-side.

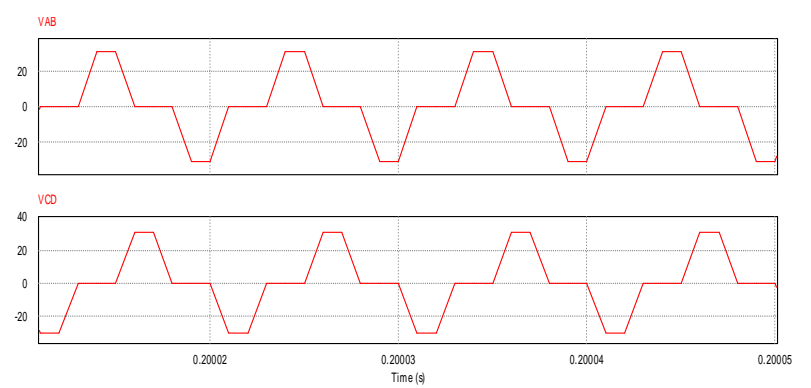

Figure 9: Simulation waveform of voltage waveforms $V_{A B}$ and $V_{C D}$.

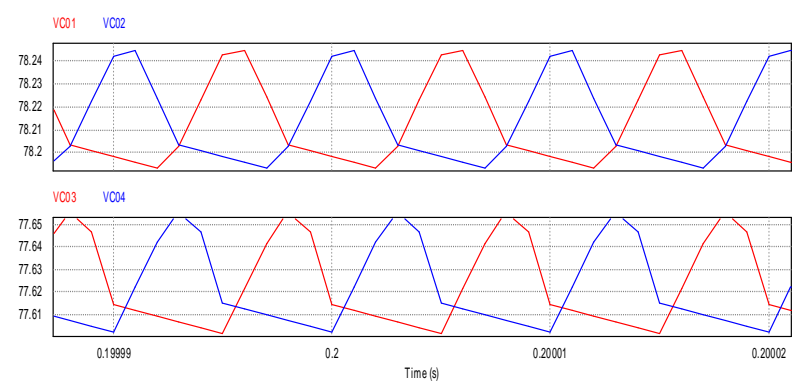

Figure 10: Voltages across output capacitors

The voltage across $\mathrm{V}_{\mathrm{AB}}, \mathrm{V}_{\mathrm{CD}}$, and the voltage across all four output capacitors are represented in Fig.9,10. From this, it's clear that each capacitor voltage is $\mathrm{V}_{\mathrm{O}} / 4$, and Fig 11 shows that the inverter output voltage, which is pure AC and fewer harmonics and THD. 


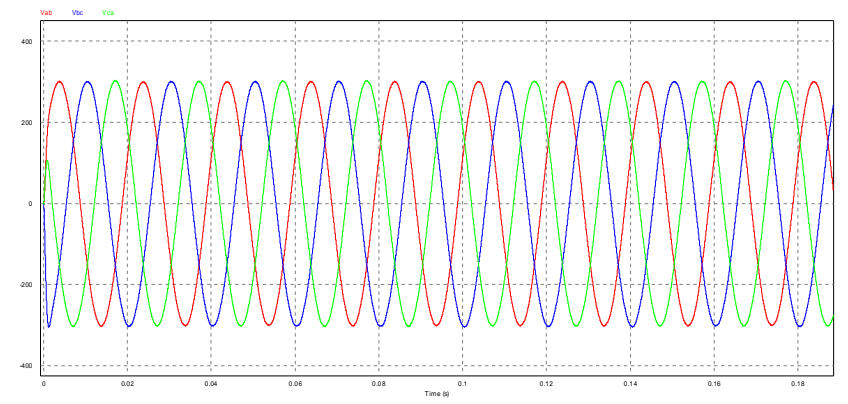

Figure 11: output voltage of Inverter

\section{CONCLUSION}

The resulting demand for this technology for an extensive range of renewable energy applications. Resources (RES) are most efficiently used in the world to achieve power output. The output energy obtained from the stack of fuel cells is stepped up with various methodologies now available to achieve further performance gain as the energy produced from them is low rated value. In this work, an attempt is made to step up the energy to get output $300 \mathrm{~V}$ with the $12 \mathrm{~V}$ input using an efficient high-phase hybrid conversion in the open-loop model via the clamping diodes. The three-level hybrid dc-dc converter boost, based on the traditional five-level inverter clamped single-phase diode, is proposed in this paper. This will not only work with the high voltage gain but also make the power switches duty cycles greater than 0.5 with the increasing voltage gain instead of the extreme duty cycles.

Furthermore, the capacitor voltages can be controlled by the proposed PWM control method in both dynamic and steady states, and the power switch is blocking voltages that are half the dc voltage of the output. The hybrid converter's average calculated efficiency is around 93.6 percent. Consequently, the converter which is proposed is suitable for fuel cell generation systems linked to electric vehicle applications.

\section{REFERENCES}

1. X. Yu, M. R. Starke, L. M. Tolbert, and B. Ozpineci, "Fuel cell power conditioning for electric power applications : a summary," IET Electr. Power Appl., vol. 1, no. 5, pp. 643-656, 2007.

2. A. Srivastava and M. Prabhakar: High gain hybrid DC-DC converter, In: Proc. of IEEE International Conference on Electrical Energy Systems, Chennai, (2014), 218-222.

3. K. B. Park, C. E. Kim, G. W. Moon, and M. J. Youn, "Non-isolated high step-up converter based on boost integrated half-bridge converter," INTELEC, Int. Telecommun. Energy Conf., vol. 2, pp. 1-6, 2009.
4. F. Barbir, "System design for stationary power generation," in Fuel Cell Technology and Application, ser. Handbook of Fuel Cells Fundamentals, Technology and applications, W. Vielsthch, H. A. Gasteiger, and A. Lamm, Eds. John Wiley and Sons, 2003, vol. 4.

5. M. Premkumar, C. Kumar and R. Sowmya, "Analysis and Implementation of high-performance DC-DC step-up converter for Multilevel boost structure," Front Energy Resear., 7 (2019), 149.

6. M. Premkumar, C. Kumar, A. Anbarasan, and R.Sowmya, “ A novel non-isolated high step-up DC-DC boost converter using single switch for renewable energy systems," Elect Engi.,102 (2020), 811-829.

7. Sundararaman K, Elavarasu R, Bindu K V "A Soft-Switched Bi-directional DC-DC Converter for a BLDC motor based Electric Vehicle," International Journal of Emerging Trends in Engineering Research, Volume8. No. 6, June 2020.

8. M Venkatesh, Dr. K Chandra Sekhar, "AC Circulating Current Control in Modular Multilevel inverter based on Estimation of Capacitor Voltages through Kalman Observer" International Journal of Emerging Trends in Engineering Research, Volume8. No.8, August 2020. 